\title{
The ADTA's First Half-Century: Ma(r)king History with an Eye to the Horizon
}

\author{
David Alan Harris ${ }^{1}$
}

Published online: 7 October 2016

(C) American Dance Therapy Association 2016

\begin{abstract}
The author, as co-editor of the American Journal of Dance Therapy, introduces six essays by a small group of experts, invited to share reflections on the social, political, economic, scientific, and cultural context for the development of the profession of dance/movement therapy (DMT) over the first half century of the American Dance Therapy Association (ADTA). Through allusions to pivotal events in the United States circa 1966, this introductory editorial characterizes the U.S. zeitgeist around the year of the ADTA's founding. Specific references are made to the signing of the Voting Rights Act, the establishment of Medicaid and Medicare, the founding of the National Organization for Women, as well as the violent targeting of civil rights marchers in Selma, Alabama, and the spontaneous launching of the modern LGBT rights movement with the Stonewall Rebellion in New York's Greenwich Village. Commentary on the six essays to follow the editorial includes discussion of DMT as a female-dominated profession, which has apparently suffered the economic consequences of gender bias. Strategies for countering devaluation of the profession and building respect for it-including improving dance/movement therapists' cultural competence, upgrading both quantitative and qualitative research, and fostering alliances between the ADTA and sister institutions-are likewise advanced.
\end{abstract}

Keywords American Dance Therapy Association - Cultural competency · Dance/movement therapy · Feminism - History · Interpersonal neurobiology · Qualitative research

David Alan Harris

ajdt.david@gmail.com

1 Chicago, IL, USA 
As a way of making history, the American Journal of Dance Therapy marks the first 50 Years of the American Dance Therapy Association (ADTA) in part with this curated collection of six historical essays. The journal's co-editors invited a small group of experts to share abbreviated reflections on a half dozen specified topics chosen to address the social, political, economic, scientific, and cultural context for the development of the profession of dance/movement therapy (DMT) over the ADTA's first half century.

The published essays themselves deserve to be read as historical documents, and with both history and the future in mind. What do the authors tell the ADTA's membership about DMT's past that may help us, collectively, as we imagine our future and move forward to address its challenges? Certainly, dance/movement therapists working in 2016 bring a diverse set of expectations and assumptions about the world and its peoples that is quite different from the possibly more homogeneous perspective of the women who first set the ADTA in motion. What are some of the salient features of the sociohistorical context in which the DMT professional association gestated, was given birth to, and pulled itself up to its proverbial feet to take its first baby steps? In order to usefully assess where the DMT profession has come from and where it ought to be headed, it may be instructive to look at the zeitgeist at the ADTA's birthing and to compare it with our own at the publication of this issue.

Landmarks of U.S. history circa 1966 are readily identified, even five decades later. Just as today, social movements at that time were actively fomenting change, seeking to redefine the geopolitical position of the U.S. in the world, and to redistribute the nation's power to address persistent and widespread inequities. The federal government's role in protecting the health and welfare of all its people was a subject of contention, and then as today the financing of mental health care generally lagged behind that for other medical concerns.

By the time the ADTA was formed, the civil rights movement had already begun to produce some of its most lasting legislative gains. When President Lyndon Baines Johnson signed the Voting Rights Act of 1965, few dreamed that five decades later-given sweeping demographic changes and an electorate in which African-American women would have come to vote at a proportionately higher rate than any other cohort nationally (Lopez \& Taylor, 2009) — the son of a Kenyan father and an Kansan mother would be in the final year of his two-term presidency. Neither would it likely have been foreseen, however, that voting rights would remain severely contested. Following a U.S. Supreme Court decision (Shelby County v. Holder, June 25, 2013) that largely gutted the 1965 act, civil rights groups today are once again having to challenge restrictive laws newly implemented in states north and south, denouncing them as implicitly designed to suppress the vote among African-Americans and other diverse constituencies (Hebert \& Lang, 2016).

While far from having permanently ushered in a golden era of racial equality in U.S. institutions, it would appear nevertheless that the courageous lunch-counter sitins, marches, and bus boycotts of the 1950s and 1960s have fostered the mainstreaming of "diversity awareness" (Ingram, 2001) as central within the national ethos. What impact has this history had on the DMT profession's evolution? Although the ADTA may not have been at the vanguard of this 
campaign, in 2008 a Multicultural and Diversity Committee was added to its Board of Directors. As DMT expands its scope in various countries across the globe, questions of fair representation and diverse leadership may continue organizationally for years to come - and especially since in the U.S. within a couple of decades persons of European descent are expected no longer to constitute a majority of the population as a whole (Colby \& Ortman, 2015).

What guidance may be drawn from the past as the ADTA shapes an equitable future in the midst of such changes? Certainly, there is evidence among DMT's early advocates and practitioners of involvement in social justice movements (ADTA Monograph, 1987). As devoted champions of putting bodies on the line, dance/movement therapists at the ADTA's founding might at the very least have engaged with a political form of kinesthetic empathy from a distance-a civil disobedience of the spirit-in response, for example, to the violent, statesponsored assault on the Black bodies seeking to cross the Alabama River via Selma's Edmund Pettus Bridge, in 1965. Similar engagement, whether virtual or more physically embodied, may be possible for dance/movement therapists in the age of social media. Today's Black Lives Matter movement-a diverse activist collective responding to the hundreds of recent police killings of young men of color in the U.S. by galvanizing popular pressure for changes to the nation's racialized criminal justice system (Ghandnoosh, 2015)_affords a compelling option. For dance/movement therapists in the U.S. today, particularly those in institutions that serve culturally diverse clienteles, such issues and commitments are far from peripheral.

Richly informed by such sociohistorical engagement, the first of the essays in the pages that follow deconstructs developments in the DMT field germane to a halfcentury of changing meanings related to a range of social classifications, including those based on race, ethnicity, language, national origin, gender, class, age, disability, sexual orientation, and gender identity. Dr. Meg Chang's commentary, Dance/Movement Therapists of Color In the ADTA: The First 50 Years, reminds DMT practitioners that understandings of what constitutes cultural competence for therapists - or, as others have properly reframed it, cultural humility (Tervalon \& Murray-García, 1998) — are very different in 2016 than they were a half-century earlier. She alludes to changes in best practice informed by trends in migration and a growing U.S. multiculturalism. The generations that initiated and established DMT deemed "colorblindness" a virtue, she suggests, and a basis for ethical and educational standards. Encouraging DMT professionals, particularly those supervisors trained in the last century, to unpack the colorblindness myth, Chang recommends replacing it, including through practitioners' ongoing self-examination and exploration of the ground of cultural competency at both the individual and collective levels.

Like Chang's essay, Dr. Christine Caldwell and Lucy Leighton's Dancel Movement Therapy, Women's Rights, and Feminism: The First 50 Years is steeped in the contemporary critique of privileges founded in race and gender. The National Organization for Women (NOW) - like the ADTA — was organized in 1966, with Betty Friedan as first president, and NOW held its inaugural national conference that same year in the nation's capital. Identifying DMT as a "female-dominated 
field," Caldwell and Leighton deliberately chart the discipline's historical development, and that of the ADTA, in relation to that of the second-wave feminist movement in the U.S. While acknowledging DMT's progress in countering psychotherapy's broader "patriarchal bias," the authors question the degree to which dance/movement therapists have successfully advanced women's rights, or taken feminism into account-citing as evidence this journal's dearth of published articles on these subjects. Caldwell and Leighton also elucidate shortcomings in second-wave feminism itself, pointing to the tendency of such figures as Friedan in the 1960s to exclude from NOW's purview issues related to women of color, lesbian, bisexual and transgender women, and women of lower socioeconomic status.

As may perhaps be inferred from the Caldwell and Leighton essay, nowhere is the difference between the sociocultural spirit of the times at the ADTA's founding and that 50 Years later more pronounced than in prevailing attitudes toward sexual minorities. Not until three years after the professional association's start did the socalled Stonewall Rebellion take place in New York's Greenwich Village-in the event that is widely agreed to have launched the modern-day movement for the civil and human rights of lesbian, gay, bisexual, and transgender people (Duberman, 1993). That several-day rebellion in June 1969, activated by a group of trans women of color who fought back against police harassment and violence during what was then a routine raid at a gay bar, is widely celebrated as having spurred a national "gay liberation" struggle to decriminalize consensual sexual expression and identity (Duberman, 1993). With countless incremental steps in the interim, Stonewall thus led in time to the U.S. Supreme Court decision, in June 2015, (Obergefell v. Hodges 2015) which legalized same-sex marriage nationwide. Fewer than 12 months after that ruling, U.S. Attorney General Loretta Lynch, the first African-American woman in that role, would passionately defend the rights of transgender people as firmly grounded in "the founding ideals that have led this country-haltingly but inexorably - in the direction of fairness, inclusion and equality for all Americans" (Phillips, 2016, para 5.). Tellingly, a few weeks after the Attorney General spoke so forthrightly on the matter of transgender equality, the ADTA (n. d.) itself issued a public statement opposing anti-LGBTQ legislation at the state level. Lynch's declaration signaled an advance in human dignity and freedom essentially unimaginable five decades before, and the ADTA in following suit has demonstrated its membership's corresponding concern for expanding social justice.

Beyond the aforementioned milestones in the developing struggle for equality regardless of race, gender, sexual orientation, or gender identity, a number of other pivotal events of the mid-1960s have contributed meaningfully to shaping the sociopolitical and economic landscape for the DMT profession in the U.S. a half century later. During the relatively brief tenure of President Johnson's Great Society, for example, legislating expanded access to healthcare through the creation of both Medicaid and Medicare was accomplished (Glass, 2007), and with decidedly less rancor than has been the case with so-called Obamacare, the Affordable Care Act of 2010.

Accordingly, Christine Hopkins, in Dance/Movement Therapy Careers amid Changing Systems: The First 50 Years, an essay that explores the economics of 
DMT, cites these groundbreaking developments in the ways that people in the U.S. access health care-balanced at either end of the half-century-as well as a number of other pivotal changes in between. Examining these matters from within the framework of postindustrial capitalism, the author discusses how changing models for health care delivery in the U.S. have affected dance/movement therapists. Many of those in the profession's early generations, she notes, practiced initially in staterun psychiatric facilities, the widespread closure of which ultimately eliminated numerous DMT jobs. In the 1980s, the rise of so-called managed care, which reapportioned access by removing relevant decision-making from medical professionals and giving that power to corporate operatives, further challenged providers, including those in DMT.

Hopkins' sources indicate that even implementation of the Affordable Care Act under President Barack Obama-despite expanding health insurance coverage to a reported 16.4 million new subscribers nationally in its first 16 months (U.S. Department of Health and Human Services, 2015)_failed to secure parity in insurance coverage for behavioral health vis-à-vis medical treatment, notwithstanding directives designed to address this disparity. She reports instead that a lack of scrutiny has meant minimal compliance with government rules that require equal access to mental health care.

Touching on a wide range of challenges faced by dance/movement therapists over the last 50 Years, Hopkins zeroes in on a fundamental lack of respect and recognition for DMT in particular within what she identifies as the already stigmatized field of the mental health professions. Pointing to the prominence of women in DMT, she protests that women remain underpaid relative to men: Women were compensated less for their work than their male counterparts when the ADTA's female founders were establishing the discipline of DMT, and the latest data underline the stubborn continuation of a gender-based pay gap (Tankersley, 2016). Dance/movement therapy's innovators had created the profession in the period after World War II, during which an estimated five million women had entered the U.S. workforce only to be largely displaced by surviving troops coming home (U.S. Department of Labor Women's Bureau, 1946). In the postwar years when DMT began to take shape, women's inclusion in the workplace and their earning capacity were still seriously contested matters. The de facto devaluing of DMT, and the financial risks faced by those who study and practice it, may be seen as an outgrowth, in part, of this structural bias against women and their work.

In this context, dance/movement therapists, whether solitary entrepreneurs or working as a collective, often with ADTA support, have developed, as Hopkins states, "adaptive strategies" for ensuring both professionalism and the profession's sustainability. Among the innovations designed to strengthen DMT have been alliances with various sister institutions. An affiliation (albeit short-lived) with the National Board of Certified Counselors, for instance, precipitated state mental health licensure for many dance/movement therapists by naming DMT a specialty of counseling. Other strategies have included working in coalition with other creative arts therapists and the "arts in healthcare movement," as well as upgrading research on DMT's efficacy as a way of establishing the discipline, at least in certain 
of its various manifestations, as firmly evidence-based practice worthy of investment by the nation's healthcare consumers.

Dr. Sherry Goodill, in her essay, Dance/Movement Therapy and the Arts in Healthcare: The First 50 Years, chronicles in some detail how representatives of the two parallel yet somewhat dissimilar disciplines have sought to collaborate for mutual benefit despite rivalries over scarce resource allocations. Goodill notes that the arts in healthcare movement emerged just a few years after the ADTA's founding. Decades later, when in her leadership role as vice president and then president of the ADTA, she sought to foster the building of relationships between the organization and related groups, and through such alliances to participate jointly in legislative advocacy at the federal level. Working in coalition, she indicates, necessitated paying attention to defusing mistrust between creative arts therapy representatives and those from various arts in healthcare organizations. Such challenges were no doubt intensified by funding limitations as well as differences associated with the respect and recognition conferred by opportunities afforded through access to such financial resources. Goodill notes that collaborative efforts nonetheless allowed for DMT's increasing integration with other services for active military personnel and veterans-large populations of federal employees seen as seriously underserved in terms of mental health programming (See, for example, S. 841, 2015).

Goodill underscores the importance for the ADTA, particularly when joining in coalition efforts with arts-in-healthcare practitioners, of clarifying boundaries in terms of scope of practice, education, and other professional parameters. Given that practitioners in both fields may pursue employment in medical settings, where patient care may be enhanced through participatory arts programming, the alliance between dance/movement therapists and persons sharing the arts within healthcare settings may prove beneficial not only in terms of strengthening these professionals' careers, but by enabling improved outcomes for participants.

The remaining two essays in this collection, rather than focusing on DMT's position relative to social institutions or its evolution as part of U.S. social history since the founding of the ADTA, discuss DMT in the context of developments in the history of scientific discoveries, methodology, and discourse during this same period. Dr. Robyn Flaum Cruz charts DMT's roots in scientific experimentation, and DMT practitioner-researchers' increasing capacity to demonstrate the discipline's effectiveness during an era when demands for evidence of this kind have become omnipresent within the U.S. healthcare system. By contrast, Dr. Cynthia Berrol focuses on the meaning and impact of one particular scientific discoverythat of "mirror neurons" - $\mathrm{a}$ finding with the potential for upgrading DMT's appraisal by those outside the profession, as well as for informing appreciation of the discipline's neurological underpinnings among dance/movement therapists themselves.

In Dance/Movement Therapy and Developments in Empirical Research: The First 50 Years, Cruz identifies a dearth of efficacy studies for psychotherapy generally until well after Marian Chace's prolonged experimentation with what has come to be called DMT. Decades later, when research into psychotherapy interventions' clinical outcomes and cost-effectiveness had become the norm, 
"evidence-based medicine" grew to be a ubiquitous demand. As calls for accountability came in turn to dominate the practice of DMT and other health professions, dance/movement therapists commonly experienced the institutional expectation for evidence of DMT's effectiveness in economic terms: Continuing services - and careers-depended on it. Cruz observes that not until after the 1970s, however, did basic scientific research into the human brain and its functions emerge - that is, after this journal's March 1977 debut, a development that her essay points to as emblematic of larger advances within DMT research.

Illuminating historical correlations as much as causality, Dr. Cruz pays special attention to ways that DMT and the research investigating it have begun to enrich scientific and medical research more broadly. She highlights shifts through time in what has come to constitute acceptable research methodology, for example. Alluding to DMT researchers' expertise in utilizing qualitative tools, she notes that in recent years the National Institutes of Health have begun to require all funded projects to incorporate qualitative as well as quantitative components in their studies' methodologies. In addition, acknowledging DMT's increasingly global profile, Cruz cites her own collaboration with the Dr. Sabine Koch (2015) in affirming how DMT researchers internationally are contributing importantly to a clinical literature that addresses "the effectiveness of body-mind interventions" ( $p$. 11 ), a field of rapidly expanding interest.

In remarking on the growth of research into the mind-body connection, the Cruz essay serves as a useful introduction to the one that follows-by her colleague, Dr. Cynthia Berrol-which more directly addresses DMT and what Siegel (2006) has aptly termed, interpersonal neurobiology. In her essay, Cruz cites today's emergent neurophysiology and neuropsychology research, and suggests that collectively it serves to strengthen DMT's claim as an evidence-based practice-in the treatment of posttraumatic distress, for instance. A number of luminaries in these fields, in addition to Siegel, including Perry (2009), Schore (2016), Porges (2011), van der Kolk (2014), and Ramachandran and Seckel (2011), have generated research questions, methodologies, and/or findings that may likewise prove of great interest to DMT professionals, as well as to others looking to comprehend DMT's unusual strengths.

Rather than examining these contributions to the latest relevant research, Berrol in her essay, Reflections on Dance/Movement Therapy and Interpersonal Neurobiology: The First 50 Years, recounts the history of her personal introduction to the mirror neurons discovery. After years of studying and publishing about DMT in relation to brain science, she initially encountered the breakthrough at a lecture by Vittorio Gallese, the eminent Italian neuroscientist whose research team had first detected and identified these neurons in the pre-motor cortex of macaque monkeys' brains. As Berrol writes, the finding that the same set of neurons fired when the subject observed another engaged in a movement as when the subject itself performed the movement "illuminated the importance of the motor system in the process of interpersonal development." As such, the neuronal-activity discovery has resonated deeply with dance/movement therapists, given a clinical practice, including widely used variants of mirroring techniques, which has been demonstrating a similar interpersonal relatedness through movement since well before the 
ADTA was ever imagined. As Berrol infers, the work of Gallese and his colleagues, like that of others advancing interpersonal neurobiology, has been deepening dance/movement therapists' theoretical understandings of the neuronal substructures to attunement, attachment, intersubjectivity, and empathy itself. Accordingly, this new research amounts to a validation of assumptions that DMT practitioners have been making about their practice since the discipline's first generation.

When read together, the essays by Drs. Cruz and Berrol, both reporting on salient examples from the great surge in scientific research into the brain over recent decades, are telling manifestations of DMT's incremental progression toward achieving the elusive aims that all of the authors in this collection seem to address, whether overtly or by inference-a heightened level of recognition and respect. By successfully embodying through their research and writing this ambition to keep moving DMT forward, the authors of all six essays in this collection help illuminate the road ahead for the ADTA's next half century of service.

Conflict of Interest The author declares that there is no conflict of interest.

\section{References}

American Dance Therapy Association (n. d.). ADTA states opposition to state bills targeting LGBTQ citizens. Retrieved from ADTA website: https://adta.org/equality/

American Dance Therapy Association. (1987). Moving in health: Selected presentations of the 22nd annual conference [Monograph No. 4].

Colby, S. L., \& Ortman, J. M. (2015). Projections of the size and Composition of the U.S. population: 2014 to 2060, Population estimates and projections. (U.S. Census Bureau Current Population Reports (P25-1143). Retrieved from https://www.census.gov/content/dam/Census/library/publi cations/2015/demo/p25-1143.pdf

Cruz, R. F., \& Koch, S. (2015). Reading and evaluating quantitative research in body psychotherapy. International Body Psychotherapy Journal: The Art and Science of Somatic Praxis, 14(1), 10-19.

Duberman, M. (1993). Stonewall. New York: Penguin Press.

Ghandnoosh, N. (2015). Black lives matter: Eliminating racial inequity in the criminal justice system. (The Sentencing Project report). Retrieved from The Sentencing Project website: http://sentencingproject.org/wp-content/uploads/2015/11/Black-Lives-Matter.pdf

Glass, A. (2007). President Johnson signs Medicare bill on July 30, 1965. Retrieved from The Politico website: http://www.politico.com/story/2007/07/president-johnson-signs-medicare-bill-on-july-301965-005129

Hebert, J. G., \& Lang, D. (2016). Courts are finally pointing out the racism behind voter ID laws. The Washington Post. Retrieved from https://www.washingtonpost.com

Ingram, P. D. (2001). An overview of diversity awareness. Pennsylvania State University College of Agricultural Sciences. [Monograph]. Retrieved from http://www.wiu.edu/advising/docs/Divers ity_Awareness.pdf

Lopez, M. H., \& Taylor, P. (2009). Dissecting the 2008 electorate: Most diverse in U.S. history. (Pew Research Center Report). Retrieved from Pew Research Center website: http://www.pewh ispanic.org/2009/04/30/dissecting-the-2008-electorate-most-diverse-in-us-history/

Obergefell v. Hodges, 135 S. Ct. 2584 (2015).

Perry, B. D. (2009). Examining child maltreatment through a neurodevelopmental lens: Clinical applications of the Neurosequential Model of Therapeutics. Journal of Loss and Trauma, 14(4), 240-255.

Phillips, A. (2016). How Loretta Lynch's speech brought some transgender advocates to tears. The Washington Post. Retrieved from https://www.washingtonpost.com

Porges, S. (2011). The polyvagal theory: Neurophysiological foundations of emotions, attachment, communication, self-regulation. New York: Norton. 
Prioritizing Veterans Access to Mental Health Care Act of 2015, S. 841, 114th Cong. (2015).

Ramachandran, V. S., \& Seckel, E. L. (2011). Synchronized dance therapy to stimulate mirror neurons in autism. Medical Hypotheses, 76(1), 150-151. doi:10.1016/j.mehy.2010.10.047.

Schore, A. (2016). Affect regulation and the origin of the self: The neurobiology of emotional development. New York: Psychology Press.

Shelby County v. Holder, 133 S. Ct. 2612 (2013).

Siegel, D. J. (2006). An interpersonal neurobiology approach to psychotherapy: How awareness, mirror neurons, and neural plasticity contribute to the development of well-being. Psychiatric Annals, $36(4), 248-256$.

Tankersley, J. (2016). U.S. household incomes soared in 2015, recording biggest gain in decades. The Washington Post. Retrieved from https://www.washingtonpost.com

Tervalon, M., \& Murray-García, J. (1998). Cultural humility versus cultural competence: A critical distinction in defining physician training outcomes in multicultural education. Journal of Health Care for the Poor and Underserved, 9(2), 117-125.

U.S. Department of Health and Human Services, Office of the Assistant Secretary Planning and Evaluation. (2015). Health insurance coverage and the Affordable Care Act, May 5, 2015. Retrieved from https://aspe.hhs.gov/sites/default/files/pdf/139211/ib_uninsured_change.pdf

U.S. Department of Labor Women's Bureau, (1946). Women workers in ten war production areas and their postwar employment plans, (Bulletin 209). Retrieved from http://njdigitalhighway.org/en j/lessons/ww_ii_industrial_production/pdf/women_workers_in_ten_war_production_areas.pdf

van der Kolk, B. A. (2014). The body keeps the score: Brain, mind, and body in the healing of trauma. New York: Viking.

\section{David Alan Harris}

BC-DMT joins Christina Devereaux in co-editing the American Journal of Dance Therapy. He studied at MCP Hahnemann University with Sherry Goodill and Gayle Gates, and worked for a time under the supervision of Arlynne Stark. He has taught the course, Social and Cultural Diversity, for Antioch University New England, and has lectured and taught on five continents about the application of dance/movement therapy in fostering recovery from torture and other severe forms of interpersonal violence. 